\title{
Modeling of Horns for Sonic/Ultrasonic Applications
}

\author{
Stewart Sherrit, Benjamin P. Dolgin, Yoseph Bar-Cohen \\ Jet Propulsion Laboratory, California Institute of Technology, Pasadena, CA \\ Dharmendra Pal, Jason Kroh, Tom Peterson \\ Cybersonics Inc., Erie, PA
}

\begin{abstract}
JPL has a requirement for telerobotic tools for planetary sample acquisition, which require low power and have the ability to work in harsh environments. We are currently investigating the possibility of using ultrasonic horns to develop a family of ultrasonic tools for these environments. In an effort to determine control parameters a one-dimensional Mason's model for a stepped ultrasonic horn assembly was developed which includes the effects of mechanical and electrical losses in the piezoelectric material and acoustic elements. The model is separated into three regions; the piezoelectric stack including stress bolt the backing layer and the horn. The model is found to predict the impedance data of the horn assembly very accurately up to the first coupled (radial) resonance. The model also allows for the calculation of the velocity and force and power delivered to each acoustic element. FEM modeling and accelerometer data from the horn tip were used to corroborate the model. The difficulties associated with modeling the load impedance of various devices will be discussed and current directions noted.
\end{abstract}

\section{INTRODUCTION}

JPL's requirement for telerobotic sample acquisition tools, which use low power and have the ability to work in harsh environments, has created an interest in novel tooling mechanisms. One of the research thrusts is in the area of ultrasonic drilling. Currently JPL in collaboration with Cybersonics is investigating the possibility of using ultrasonic horns to develop an ultrasonic drill for these environments. In an effort to determine control parameters we have used Mason's equivalent circuit to model the stepped ultrasonic horn assembly.

Analytical solutions to the wave equation in piezoelectric materials can be quite cumbersome to derive from first principles in all but a few cases. Mason[1],[2] was able to show that for one-dimensional analysis that most of the difficulties in deriving the solutions could be overcome by borrowing from network theory. He presented an exact equivalent circuit that separated the piezoelectric material into an electrical port and two acoustic ports through the use of an ideal electromechanical transformer. The model has been widely used to model free and mass loaded resonators[3], transient response[4], material constant determination[5], and a host of other applications including ultrasonic horns[6]. In the following section we describe an equivalent circuit for a transducer with two layers of backing a piezoelectric stack with a stress bolt mechanically in parallel and a three layered stepped horn. A schematic of the horn assembly is shown in Figure 1.

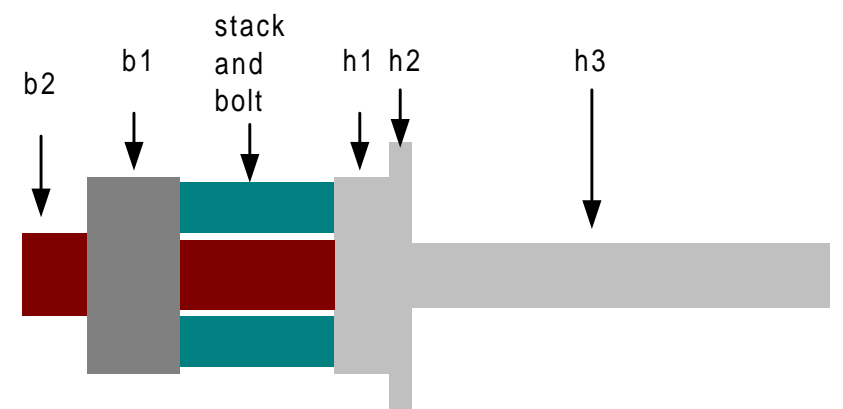

Figure 1: Schematic of the horn, stack with stress bolt and backing layers. Relative dimensions are to scale.

\section{DESCRIPTION OF THE MODEL}

The ultrasonic horn shown in Figure 1 can be broken down into three general regions. The piezoelectric stack and stress bolt, the backing layers on the back face of the transducer and the horn on the front face of the transducer. In order to proceed with modeling each of the three elements of the ultrasonic horn are modeled and studied independently. The assembly is then studied as a whole.

\section{A. Piezoelectric Stack and Stress Bolt.}

The piezoelectric stack and stress bolt are modeled using Mason's equivalent circuit for a length extensional resonator. In order to accomplish this we use the network representation of a non-piezoelectric solid acoustic element as described by Redwood[4] and McSkimmin[7]. For the horn we have chosen to model, the stress bolt is of the order of 1/6 the mechanical impedance of the piezoelectric stack. Since the impedance is smaller we have assumed a constant strain in the piezoelectric stack and the stress bolt. This means acoustic elements in Mason's equivalent circuit should be added in series for the piezoelectric and the stress bolt. The equivalent circuit for the stress bolt and the stack is shown in Figure 2. The area of the stack is $A=\pi\left(r_{2}^{2}-r_{1}^{2}\right)$ and the total length of the stack and stress bolt is $\mathrm{L}=\mathrm{nt}$. where $\mathrm{n}$ is the number of layers in the stack $t$ is the thickness of the layer. The 
parameters of the Mason's equivalent circuit for the ring stack and stress bolt shown in Figure 2 are.

$$
\begin{array}{r}
C_{0}=\frac{n^{2} \varepsilon_{33}^{T} A}{L}\left(1-k_{33}^{2}\right) \\
N=\frac{n A}{L} \frac{d_{33}}{s_{33}^{E}} \\
Z_{S}^{S B}=\frac{Z_{0}^{S B}}{i \sin \left(\Gamma^{S B} L\right)} \\
Z_{S}^{P}=\frac{Z_{0}^{P}}{i \sin \left(\Gamma^{P} L\right)} \\
Z_{T}^{S B}=i Z_{0}^{S B} \tan \left(\Gamma^{S B} \frac{L}{2}\right) \\
Z_{T}^{P}=i Z_{0}^{P} \tan \left(\Gamma^{P} \frac{L}{2}\right)
\end{array}
$$

where $Z_{0}=\rho v A$ is the specific acoustic impedance which is the product of the density, velocity and area of the acoustic element. The superscripts designate whether the value corresponds to the stress bolt SB or the piezoelectric $\mathrm{P}$. $\Gamma=\omega / v$ is the complex propagation constant for each material where $v$ is the velocity of the acoustic element The velocity of the piezoelectric is $v=\left(1 / \rho s_{33}\right)^{1 / 2}$ where $s_{33}$ is the complex open circuit compliance in the poling direction. The velocity of the stress bolt is

$$
\mathrm{v}=\left(\frac{Y}{\rho}\right)^{1 / 2}
$$

where $\mathrm{Y}=\mathrm{Y}(1+\mathrm{i} / \mathrm{Q})$ is the complex Young's modulus. $\mathrm{Q}$ is is the mechanical $\mathrm{Q}$ of the material.

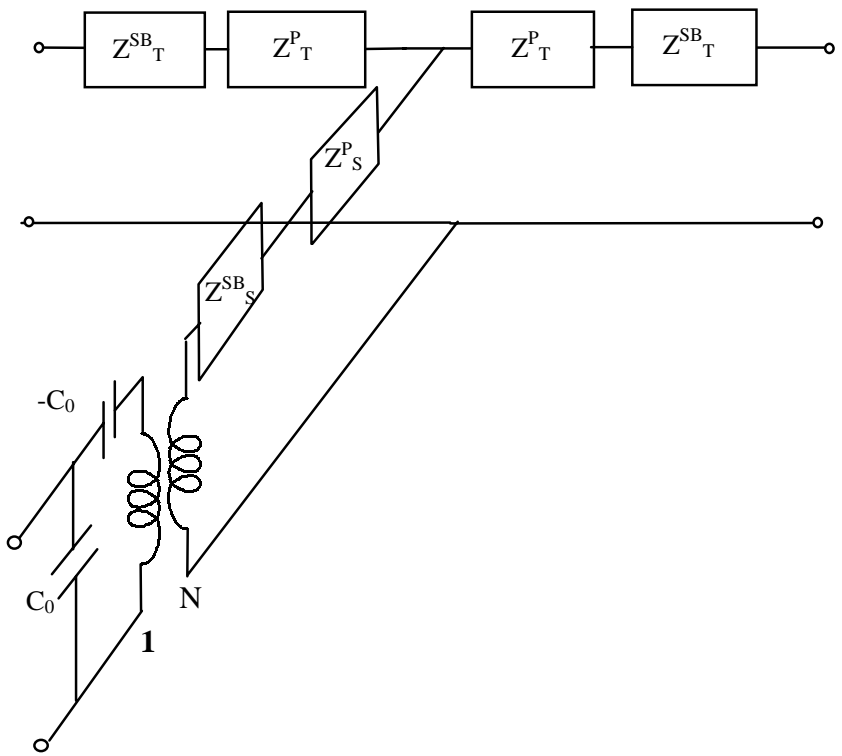

Figure 2. Mason's equivalent circuit for a piezoelectric ring stack with a center stress bolt. Parameters are shown in (1) to (7).
It should be noted that (7) is an approximation due the finite length of the stack.

\section{B Backing layers}

The backing layer can be represented by two acoustic elements with matched boundary conditions as is shown in Figure 3.

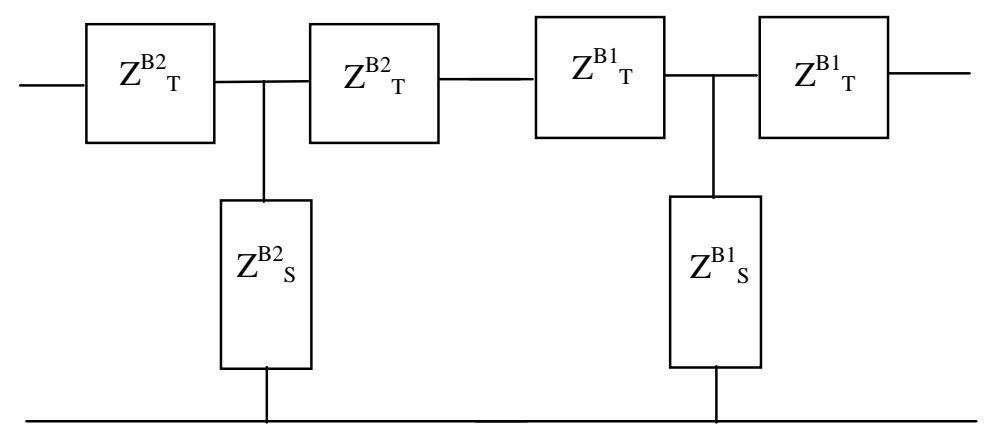

Figure 3. Network representation of backing layers

The elements of the acoustic network of the backing layer are.

$$
\begin{gathered}
Z_{T}^{B 1}=i Z_{0}^{B 1} \tan \left(\Gamma^{B 1} \frac{b_{1}}{2}\right) \\
Z_{S}^{B 1}=\frac{Z_{0}^{B 1}}{i \sin \left(\Gamma^{B 1} b_{1}\right)} \\
Z_{T}^{B 2}=i Z_{0}^{B 2} \tan \left(\Gamma^{B 2} \frac{b_{2}}{2}\right) \\
Z_{S}^{B 2}=\frac{Z_{0}^{B 2}}{i \sin \left(\Gamma^{B 2} b_{2}\right)}
\end{gathered}
$$

where $b_{i}, Z_{0}^{i}, \Gamma^{i}$ are the length, specific acoustic impedance and complex propagation constant of the $i^{\text {th }}$ layer. The total acoustic impedance of the backing stack and stress bolt up to the center of the acoustic transmission line is

$$
Z_{L}=Z_{T}^{S B}+Z_{T}^{P}+Z_{T}^{B 1}+\left(\frac{Z_{S}^{B 1}\left(Z_{T}^{B 1}+Z_{T}^{B 2}+\frac{Z_{T}^{B 2} Z_{S}^{B 2}}{Z_{S}^{B 2}+Z_{T}^{B 2}}\right)}{Z_{S}^{B 1}+Z_{T}^{B 1}+Z_{T}^{B 2}+\frac{Z_{T}^{B 2} Z_{S}^{B 2}}{Z_{S}^{B 2}+Z_{T}^{B 2}}}\right)
$$

\section{Horn}

The horn equivalent circuit is similar to the model for the backing layer except an additional layer is present. It is interesting to note that the magnification of the stepped horn discussed by Belford[8] is inherent in the network representations of the acoustic elements. The acoustic layers are shown in Figure 4. Each layer in the horn is a T network 
of the tan and sin functions, however due to space limitations of we show the $\mathrm{T}$ network as a single three port element.

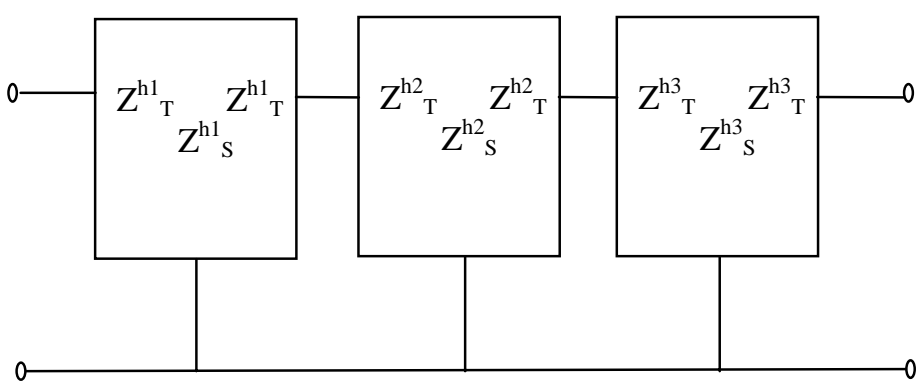

Figure 4. The equivalent circuit of the horn.

The acoustic impedance of the right side of the acoustic transmission line which includes the unloaded, unclamped horn is

$$
\begin{aligned}
& Z_{R}=Z_{T}^{S B}+Z_{T}^{P}+Z_{T}^{h 1} \\
& +\left(\frac{Z_{S}^{h 1}\left(Z_{T}^{h 1}+Z_{T}^{h 2}+\frac{Z_{S}^{h 2}\left(Z_{T}^{h 2}+Z_{T}^{h 3}+\frac{Z_{T}^{h 3} Z_{S}^{h 3}}{Z_{T}^{h 3}+Z_{S}^{h 3}}\right)}{Z_{S}^{h 2}+\left(Z_{T}^{h 2}+Z_{T}^{h 3}+\frac{Z_{T}^{h 3} Z_{S}^{h 3}}{Z_{T}^{h 3}+Z_{S}^{h 3}}\right)}\right)}{\left.Z_{S}^{h 1}+Z_{T}^{h 1}+Z_{T}^{h 2}+\frac{Z_{S}^{h 2}\left(Z_{T}^{h 2}+Z_{T}^{h 3}+\frac{Z_{T}^{h 3} Z_{S}^{h 3}}{Z_{T}^{h 3}+Z_{S}^{h 3}}\right)}{Z_{S}^{h 2}+\left(Z_{T}^{h 2}+Z_{T}^{h 3}+\frac{Z_{T}^{h 3} Z_{S}^{h 3}}{Z_{T}^{h 3}+Z_{S}^{h 3}}\right)}\right)}\right)
\end{aligned}
$$

For a given harmonic force on the front face of the horn the velocity $\mathrm{v}$ and the displacement $\mathrm{d}=\mathrm{v} / \mathrm{i} \omega$ of the tip of the horn can be determined by finding the current through the acoustic impedance $\mathrm{Z}_{\mathrm{T}}^{\mathrm{h} 3}$ at the end of the horn. The total acoustic impedance for the case where the front and back acoustic ports are shorted (free to expand)

$$
Z_{A}=Z_{S}^{S B}+Z_{S}^{P}+\frac{Z_{R} Z_{L}}{Z_{R}+Z_{L}}
$$

where $Z_{L}$ and $Z_{R}$ are the sum of the acoustic impedances on the left and right side of the piezoelectric material as defined in (12) and (13). The total electrical impedance as seen from the electrical port is

$$
Z=\frac{Z_{C}\left(\frac{Z_{A}}{N^{2}}-Z_{C}\right)}{\frac{Z_{A}}{N^{2}}}=Z_{C}-\frac{Z_{C}^{2} N^{2}}{Z_{A}}
$$

where $Z_{C}=1 / i \omega C_{0}$. And $N$ is the turns ratio defined in (2). The properties of the elements of the horn are shown in Table
1. We have used the unclamped velocity in the model since at these frequencies the elements are not laterally clamped. That is we have used $v=(Y / \rho)^{1 / 2}$ where $Y$ is the Young's modulus and $\rho$ is the density. In order to test the horn response a two layer stepped horn was modeled in ANSYS 5.4 and the magnification and resonance frequency of the

\begin{tabular}{|c|}
\hline Piezoelectric Stack \\
\hline $\begin{array}{c}\text { ID. }=0.0125 \mathrm{~m} \quad \text { OD. }=0.025 \mathrm{~m} \quad \mathrm{~L}=0.0212 \mathrm{~m} \\
\rho=7800 \mathrm{~kg} / \mathrm{m}^{3} \mathrm{n}=4 \\
\mathrm{~d}_{33}=280(1-0.0008 \mathrm{i}) \mathrm{pC} / \mathrm{N} \\
\varepsilon^{\mathrm{T}}{ }_{33}=1.09 \times 10^{-8}(1-0.0015 \mathrm{i}) \mathrm{F} / \mathrm{m} \\
\mathrm{s}_{33}^{\mathrm{E}}=2.0 \times 10^{-11}(1-0.0012 \mathrm{i}) \mathrm{m}^{2} / \mathrm{N}\end{array}$ \\
\hline $\begin{array}{c}\text { Stress Bolt } \\
\text { OD. }=0.00952 \mathrm{~m} \quad \mathrm{~L}=0.0212 \mathrm{~m} \quad \rho=7890 \mathrm{~kg} / \mathrm{m}^{3} \\
\mathrm{v}=4970(1+0.001 \mathrm{i}) \mathrm{m} / \mathrm{s}\end{array}$ \\
\hline Backing Layer 1 \\
\hline $\begin{array}{c}\text { OD. }=0.0268 \mathrm{~m} \quad \mathrm{~L}=0.0127 \mathrm{~m} \quad \rho=7890 \mathrm{~kg} / \mathrm{m}^{3} \\
\mathrm{v}=4970(1+0.001 \mathrm{i}) \mathrm{m} / \mathrm{s} \\
\text { Backing Layer } 2\end{array}$ \\
\hline $\begin{array}{c}\text { OD. }=0.011 \mathrm{~m} \quad \mathrm{~L}=0.00902 \mathrm{~m} \quad \rho=7890 \mathrm{~kg} / \mathrm{m}^{3} \\
\mathrm{v}=4970(1+0.001 \mathrm{i}) \mathrm{m} / \mathrm{s}\end{array}$ \\
\hline $\begin{array}{c}\text { Horn Layer } 1 \\
\text { OD. }=0.0268 \mathrm{~m} \quad \mathrm{~L}=0.00775 \mathrm{~m} \quad \rho=4430 \mathrm{~kg} / \mathrm{m}^{3} \\
\mathrm{v}=5150(1+0.0006 \mathrm{i}) \mathrm{m} / \mathrm{s} \\
\text { Horn Layer } 2\end{array}$ \\
\hline $\begin{array}{c}\text { OD. }=0.0366 \mathrm{~m} \quad \mathrm{~L}=0.00325 \mathrm{~m} \quad \rho=4430 \mathrm{~kg} / \mathrm{m}^{3} \\
\mathrm{v}=5150(1+0.0006 \mathrm{i}) \mathrm{m} / \mathrm{s} \\
\text { Horn Layer } 3\end{array}$ \\
\hline $\begin{array}{c}\text { OD. }=0.00890 \mathrm{~m} \quad \mathrm{~L}=0.0583 \mathrm{~m} \quad \rho=4430 \mathrm{~kg} / \mathrm{m}^{3} \\
\mathrm{v}=5150(1+0.0006 \mathrm{i}) \mathrm{m} / \mathrm{s}\end{array}$ \\
\hline
\end{tabular}
horn was found to match values predicted values from the one dimensional analysis of the horn structure.

Table 1. Properties of the horn elements used in the modeling

The impedance of the horn was measured as a function of frequency using a Solatron 1260 Impedance Analyzer. The data and the predicted impedance data are shown in Figure 5. The predicted impedance data was generated using equation 15 and the properties in Table 1. As can be seen the fit is very good around the first two resonances. The peak in the impedance spectra at $45 \mathrm{kHz}$ was thought to be due to the ring-breathing mode of the piezoelectric stack. The first resonance peak at about $20 \mathrm{kHz}$ is the resonance of the horn tip. The resonance at $35 \mathrm{kHz}$ is associated with resonance of the full assembly (horn, backing and stack). The slight mismatch in the reactance data at the resonance of the horn $(35 \mathrm{kHz})$ tip is due to the large $\mathrm{Q}$ of the resonators. If the data is measured on a finer frequency scale a better visual match to the data is observed. The coefficients used to 

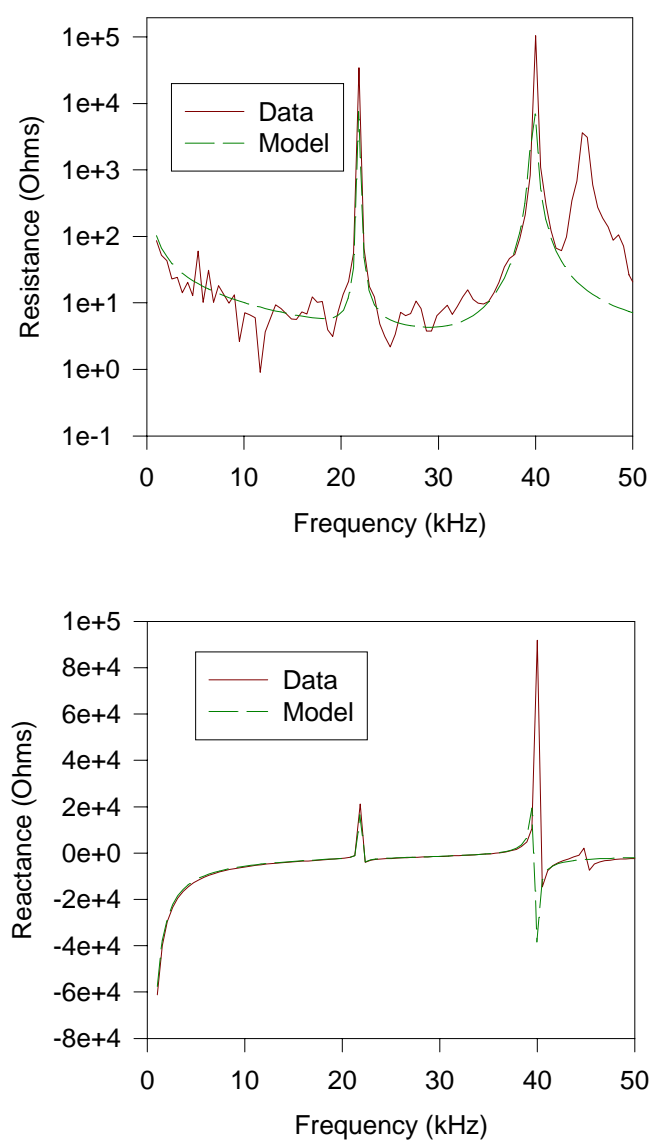

Figure 5. The impedance data of the horn and the predicted impedance using equation 15 with the data in Table 1.

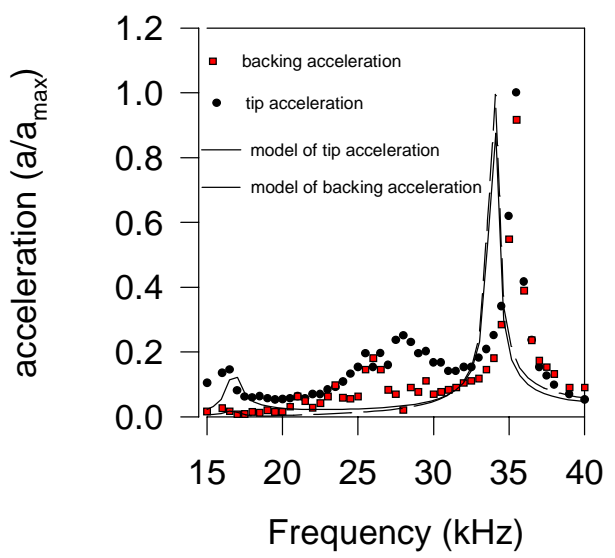

Figure 6. The measured acceleration response of the horn tip and backing face compared to response calculated from the model.

determine the impedance data could also be used to determine the velocity of the front face, displacement of the horn tip and power delivered to the horn however it should be noted that impedance data is small signal data. The response of the system and the losses can change considerably under high fields.

The acceleration of the front and back face of the horn assembly was measured with a pair of Endevco 2292 accelerometers. The frequency response is shown in Figure 6 along with the response predicted by the model. In the model we have added an impedance $\mathrm{Z}=\mathrm{im} \omega(\mathrm{m}=$ accelerometer mass) to the front and back acoustic ports to account for the mass damping of the accelerometers. An example of the current-voltage relationship for an unloaded horn is shown in Figure 7. The tuned load is resistive with an impedance of 50 ohms.

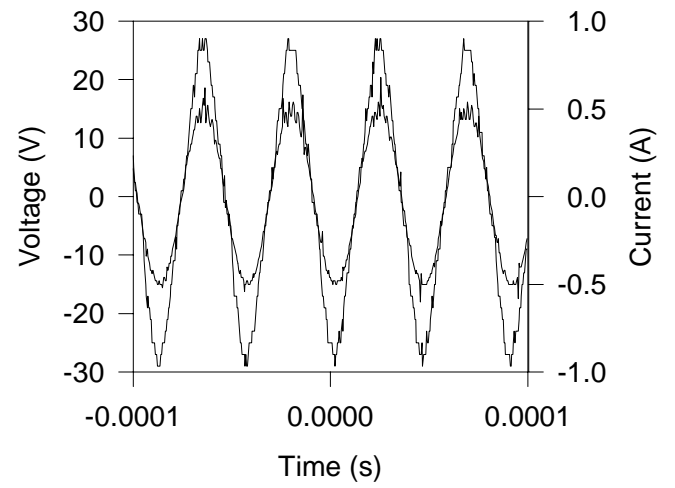

Figure 7. The voltage and current for the horn driven at low fields. The average power is 6 Watts. The frequency is 22 $\mathrm{kHz}$.

\section{EFFECT OF LOAD}

In the current drill design by Cybersonics an ultrasonic horn driven at $20-23 \mathrm{kHz}$ is used to excite a free floating drill or coring bit into various rock samples. The action is similar to a jackhammer impact. Although the electrical drive is of the order of $20 \mathrm{kHz}$, considerable low frequency components are present in the drill. The load on the horn tip is non linear and substantial subharmonics are produced which aid in the drilling process. A schematic diagram of the drill assembly is shown in Figure 8. The drill is in contact with the horn tip and is driven from the horn at the horn tip velocity. The tip of the drill or corer is impacted into the rock sample creating stress fracture in the material. An optional restoring spring is used to aid in returning the drill base to the horn tip where the action is repeated. A free mass between the horn and drill bass was found to increase the low frequency energy transfer as well as reduce the dependence of the drilling rates on the drill stem length. 


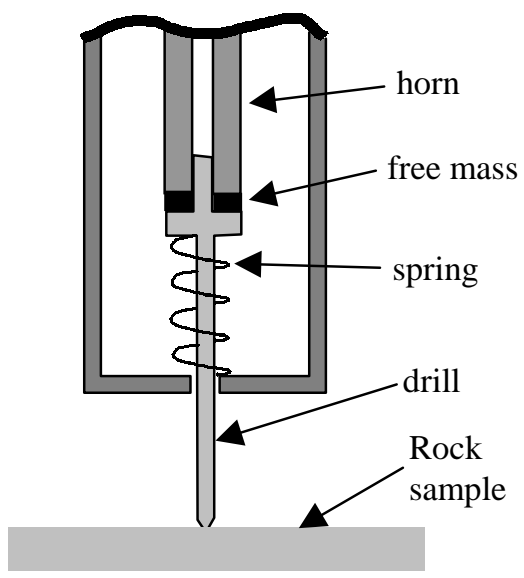

Figure 8. Schematic cross section of the drill assembly with restoring spring and impedance matching mass.

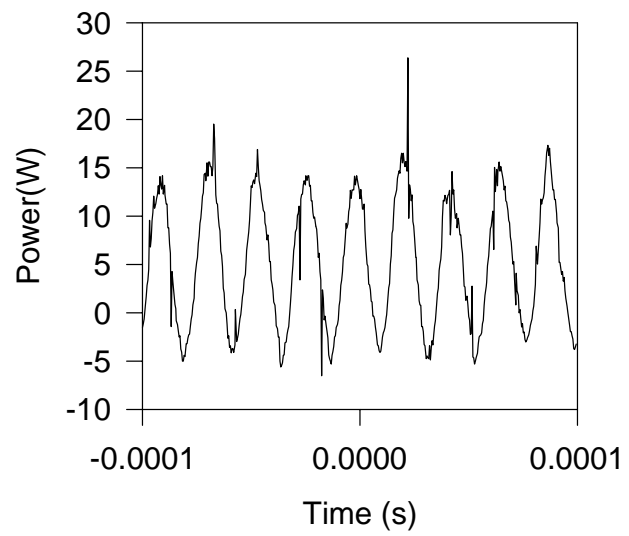

Figure 9. The power to the horn assemble during drilling into construction brick with a tungsten carbide steel rod $(2.75 \mathrm{~mm}$ diam) and a 4 gram free mass. The average consumed power was 5.3 watts. The drill rate was $0.1 \mathrm{~mm} / \mathrm{s}$.

The ultrasonic/sonic drill has been shown to drill into diorite, magnetite, sandstone, limstone, basalt, ice, silicon and construction brick with low axial load and torque. The power dissipated in the drill while drilling into construction brick is shown in Figure 9. The average power dissipated in this case is 5.3 watts.

Measurements of the accoustic power spectrum in the rock samples as well as audible noise during drilling indicates a substantial low frequency component in the drill bit. Current efforts are underway to model the source of these low frequency components.

\section{CONCLUSIONS}

The equivalent circuit for a stepped horn actuator assembly was presented including the stress bolt and backing layers. The model was compared to experimental data for a standard horn design. Impedance and acceleration data from the horn were found to agree very well with the impedance and acceleration predicted by the model. The horn was used to actuate an ultrasonic/sonic drill design by Cybersonics Ltd. The drill was shown to drill in both hard and soft rock samples at power levels of 5 Watts. Test results from the drill indicate that it may be a suitable candidate for a rover based sampling system due to the small axial loads and torque associated with this drill

\section{ACKNOWLEDGMENT}

The research at the Jet Propulsion Laboratory (JPL), a division of the California Institute of Technology, was carried out under a contract with the National Aeronautics Space Agency (NASA).

\section{REFERENCES}

[1] W..P. Mason, Electromechanical Transducers and Wave Filters, Princeton, NJ, Van Nostrand, 1948

[2] W.P. Mason, Physical Acoustics and the Properties of Solids, D. Van Nostrand Co., Princeton, NJ, 1958

[3]D. A. Berlincourt, D.R. Curran, H. Jaffe, "Chapter 3Piezoelectric and Piezomagnetic Material and their Function in Transducers, pp. 169-270, Physical Acoustics-Principles and Methods, Volume 1-Part A, ed. W.P. Mason Academic Press, New York, 1964

[4] M. Redwood, "Transient Performance of a Piezoelectric 33, pp.527-536, 1961

[5] S. Saitoh, H Honda, N. Kaneko, M. Izumi, S. Suzuki, The Method of Determining $\mathrm{k}_{\mathrm{t}}$ and $\mathrm{Q}_{\mathrm{m}}$ for low $\mathrm{Q}$ piezoelectric materials" Proceedings of the IEEE Symposium on Ultrasonics, San Francisco, CA, pp. 620-623, 1985

[6] A. Bangviwat, H.K. Ponnekanti, R.D. Finch, "Optimizing the performance of piezoelectric drivers that use stepped horns", J. Acoust. Soc. of America, 91, pp. 1223-1229, 1991

[7] H.J. McSkimmin, Ultrasonic Methods for Measuring the Mechanical Properties of Liquids and Solids, Volume 1-Part A, ed. W.P. Mason Academic Press, New York, 1964 [8] J.F. Belford, "The Stepped Horn", Proc. Natl. Electronics Conference, 16, Chicago, pp.814- 822, 1960 